the maxillaries in front of the orbits. Their molar teeth were of a simple Palæotheroid type, and the incisors and canines were very much reduced. Their fore feet had four and the hind feet three short stout toes. These animals which, according to the correct rules of nomenclature, should constitute the family Titanotherida, became extinct, apparently without successors, in the Miocene age.

In the Pliocene period, Rhinocerotida, in the form of Aceratherizm and Aphelops, were still abundant, though towards the end of the period they became entirely extinct. True rhinoceroses, like those of the Old World with median horns, have never been met with in America. Remains of tapirs are also found but sparingly, and a great development took place in the various forms of three-toed horses, Protohippus and Hipparion, which replaced the Anchitherium of the Miocene. These in their turn gave way to true horses, of which remains of several species have been found in Pleistocene deposits, and scattered throughout almost every region of the Continent from north to south. These also became entirely extinct before the discovery of America by the Spaniards, a most remarkable circumstance when the fitness of the country for their maintenance, proved by the facility with which the descendants of horses introduced by the invaders have multiplied in a feral state, is considered. The tapir, in several modifications, still lingers in some districts of South and Central America, the sole direct representative of the vast and varied perissodactyle fauna of ages long gone by.

The remains of Artiodactyles in the bitherto explored American Eocenes are very scanty and unsatisfactory as affording indications of their characters. Towards the close of the period only do we find evidences of well-defined selenodont (Agriocharus) and bunodont (Elotherium and Platygonus) forms. No species corresponding to the European Anoplotherium, Dichodon, or Xipodon, have been discovered. During the Miocene period, however, Artiodactyles of both types abounded in North America. The selenodonts were chiefly represented by Oreodon, and the allied earlier and more generalised Agriocherus. These were numerous in species and individuals, but they became nearly extinct by the end of the Miocene, only surviving in the form of Merychyus, the most modified form of the group, into the Pliocene. The first indication of the camel-like animals appears in this period in the form of Poëbrotherium; also a few of the generalised Pecora are now met with, allied somewhat to Tragulina, as Leptomeryx, Hypisodus, and Hypertragulus, the latter a very minute species, but no true deer, Bovida or even Traguli, and no giraffes, Helladotheria or Sivatheria. The bunodonts were chiefly species of Elotherium, and an allied four-toed form, Pelonax, remarkable for hornlike lateral processes on its lower jaw, near the symphysis. Peccary-like forms also are now met with. In the Pliocene or Pleistocene periods, except the somewhat problematical Cosoryx, founded on some branched horn cores or antlers of a form perhaps allied to Antilocapra from the Niobrara Pliocene, all the animals can be assigned to existing families. Of the Suina, all belong to Dicotyles, or Peccary (which had formerly a more northern range than at present), or to the allied genus Platygonus, no true Sus, or Phacocharus, Babirussa, or Hippopotamus, having been found. Thus the American bunodont Artiodactyles, instead of undergoing great and diverse modifications as did the corresponding animals of the Old World, have been gradually dwindling and contracting to the two closely allied species of Peccary, amongst the smallest and most insignificant of all the pigs, and a very old form, having existed (if teeth alone are sufficient evidence) since the Miocene age. The Camelida, on the other hand, appear to have flourished, the species being numerous, and the individuals attaining very large dimensions. It is probable, in fact, that the family may have originated here, as a tolerably complete series of transitions have been traced from the Miocene Poëbrotherizm, through Procamelus and Pliauchenia, to the modern Llamas, which, though now confined to the south, once overran the North American Continent. If this view is correct, the Asiatic camels must have come into that country by immigration. A few traces of Cervida have been found in American Pliocenes, but their paucity, compared with the Old World, until the Pleistocene epoch, would lead to the belief that they cannot have originated there, but must have been imported from other lands. The same applies to the hollow-horned ruminants, of which no forms different from those now existing have been found in the fossil state.

(To be continued.)

\section{THE EFFECTS OF THE SUN'S ROTATION AND THE MOON'S REVOLUTION ON THE EARTH'S MAGNETISM}

WHEN the mean horizontal force of the earth's magnetism for each day of the year has been deduced from well-corrected observations of the bifilar magnetometer, and the results have been projected in the usual way, the curves thus obtained show successions of maxima and minima occurring in some instances at nearly equal intervals and in others abruptly and apparently without law. It has been found that these changes are experienced similarly at all stations where observatories have been placed on the earth's surface ; they are therefore variations of the magnetic force of the whole earth. The results now considered, though derived from the observations at a single station, may thus be accepted as true generally for all places.

In the projection of the ciaily mean forces observed at Makerstoun in I844, the first and last quarters of the year showed large oscillations of the earth's magnetic force, the maxima occurring near the times of new moon and the minima near those of full moon; the ranges of the oscillations were not equally great, and the oscillation disappeared in the months near midsummer. The mean result for the whole year seemed to show that great changes of the earth's magnetic force were due to the moon's position relatively to the earth and sun; but no explanation could be offered for the apparent irregularities in the lunar action. Eleven years later (in 1857), while discussing observations made near the equator, I became persuaded that the variations in question were really due to the sun's rotation on his axis. The result of a re-examination of the Makerstoun observations gave a mean period of nearly twenty-six days for the most probable duration of the magnetic oscillation.

Astronomers who till then had occupied themselves with the determination of the time of the solar rotation had found for it from $27 \cdot 3$ to $27 \cdot 7$ days. It was difficult, in the face of this result, to suppose that the magnets were better acquainted with the true time of the sun's rotation than the eminent observers, who, with the best telescopes, had watched the movement of the solar spots; and it was suggested that a movement of the sun's magnetic poles might explain the difference of the periods obtained. More recently, however, it has been found that the spots give considerably different times for the sun's rotation, and especially that those nearest the solar equator indicate, as Spoerer has shown, a period of 26.3 days, thus approaching nearly to that obtained previously from the magnetic observations. Dr. Hornstein, director of the Prague Observatory, discovered, independently, nearly the same period from his observations in 1870 .

There still remained for explanation the irregularities already noticed in the lengths and ranges of single oscillations. I, on a reconsideration of all the discussions previously made by him, arrived some time ago 
at the conclusion that the results obtained for the solar and lunar actions did not exclude each other, but that both sun and moon were concerned in the changes of the earth's magnetic intensity; and that possibly the variations in the character of the single oscillations were due to the sun and moon sometimes acting in the same and sometimes in opposite directions; just as in the case of the oceanic tides, for which the differences would be even greater were the solar more nearly equal to the lunar action.

This conclusion is put to the test ; the mean variations derived from the observations for each of two successive years are calculated for periods of 26 , of $27^{\prime} 3$, and of $29^{\circ} 53$ days, the two latter being the times of the lunar, tropical, and synodical revolutions respectively. The variations for each of these three periods corresponding to the positions of the moon and of a given solar meridian for each day of the year are then added together; the sums should represent the total actions of the two bodies for each day, and if no other causes are in question, they should agree with the observed variations.

I have shown that when the calculated results are projected so as to form a red curve, on the same mean line as a black curve representing the observations, the two agree very nearly with each other throughout the two years. The different durations and ranges of single oscillations, and the total disappearance of the latter in certain months, are found to be produced, as was supposed, by the greater or lesser agreement or opposition of the three actions.

These results demonstrate, I think, not only that the sun's rotation and the moon's revolutions produce variations of the earth's magnetic force, but that all the marked variations are really due to these causes.

There appears to be one exception to the generality of this conclusion, in sudden great changes, generally diminutions, of the earth's magnetism, which appear of variable magnitude and apparently at irregular intervals. have examined these cases, and find that if a considerable diminution of intensity happen suddenly when a given solar meridian is in the same plane with the earth, that a similar sudden diminution generally occurs twentysix days or some multiple of twenty-six days after, when the same solar meridian and the earth are again in the same plane. In one case the sudden loss of force begins five times in succession at the exact interval of twenty-six days.

If we examine these cases of successive disturbance when a given solar meridian arrives opposite the earth, we are induced to conclude either that the solar action exists only for this position, that is to say, that the earth is its cause; or that the action is continuous, but, unlike light and heat, is propagated only in one direction (or plane); or, which seems more probable, that the medium through which these actions are transmitted proceeds from the sun, is not uniformly distributed around it, nor always distributed in the same way. This idea may aid in explaining many facts in terrestrial magnetism for which hitherto no clue has existed.

We arrive then at the conclusions that the variations of the daily mean magnetic force are due to causes external to the earth, depending on the sun's and moon's motions; that all the principal variations of this force can be calculated approximately for each day in twelve months, on the hypothesis that the actions of these bodies are constant throughout the year for the same positions relative to the earth; and that the great magnetic disturbances (accompanied by the aurora borealis) are due to actions proceeding from certain parts of the sun's surface, since so many of them repeat themselves at intervals of twenty-six days, when the same solar point returns opposite the earth. It appears from other investigations that the sun's rotation produces marked effects on our atmosphere.
J. ALLAN BROUN
PHYSTCAL SCTENCE IN SCHOOLS

$W^{E}$

have received the following important communications on this subject:-

Dr. Watts has shown in last week's NATURE, p. 3Ir, how the Regulations of the Oxford and Cambridge Schools Examination Board affect injuriously the interests of science in certain schools, viz., those in which boys have "studied science instead of the older wellestablished subjects of classics and mathematics."

But it is fair to say that these are not the schools which are common in the country, even if they are to be found at all ; and the business of the Board was rather to examine effectively what schools profess to teach, than to direct their studies into a new line.

I do not think, or mean to say, that the Board and the headmasters, who are believed to have influenced its regulations, have acted in the interests of science altogether; but the way they have damaged its interests in all the principal schools of the country is not by making it "a refuge of fools," as Dr. Watts suggests.

I will, with your permission, point out how the Regulations affect the position of science at Rugby and similar schools.

The main inducement a boy has to go in for a certificate is to be excused the "Little go," if he is going to Cambridge ; or "Responsions," if he is going to Oxford. To be excused any part of the Little go he must pass in Latin, Greek, Elementary Mathematics, and Scripture Knowledge; to be excused the whole of it, he must also pass in Additional Mathematics. And since four subjects are all that is required, these four or five are all that he will take up. To be excused Responsions, he must pass in Latin, Greek, and Elementary Mathematics, and in some one other subject. Naturally, he selects the easiest. This will be French, or Scripture Knowledge, or History, or English, according to his tastes. That the three last of these subjects are easier than any Natural Science is certain. All boys know something of them; they are not wholly new to any boy, and it is at any rate commonly believed here that boys have passed and obtained distinctions in them with very great ease. And boys have probably learned French for the last eight years of their lives.

It follows that boys destined for Oxford who know something of science do not take it up, as it would be profitless to do so, unless it is distinctly easier to them than any other subject they could select as a fourth subject; and boys destined for Cambridge do not take it at all.

It should also be observed that though the examina= tion papers last year were very easy, yet the range they cover is rather large. What does "the Elementary Parts of Inorganic Chemistry" mean? This can only be discovered by a study of the examination papers. And certainly the wording is loose enough to enable the examiners to set harder papers, if it is found that the boys can do them.

The only important alteration in the description of the examination in Natural Science that I would make is a very obvious one, and one that might at once be made if any of the headmasters on the Committee would care to ascertain and represent to the University Board the interests of science at schools. It is to divide Group IV. like Group II., making the present part the elementary subjects, and adding to it an additional subject, viz., a practical examination in analysis (inorganic, qualitative), as necessary to be passed by those who wish to gain honours in science. To make this change would at any rate be a guide to a sound opinion on teaching science, though, while the grouping remains as it is, few boys will trouble the examiners.

The study of science at schools has now, it seems to me, entered on a fresh and not altogether unhealthy phase. Ten or twelve years ago there was an outcry for 